\title{
Characterization of Hot Deformation of CW602N Brass
}

\author{
S. Spigarelli*, M. El Mehtedi and M. Cabibbo \\ DIISM, Università Politecnica delle Marche, via Brecce Bianche 60131 Ancona, Italy
}

\begin{abstract}
Alpha brasses (in principle single-phase solid solution alloys containing less than $35 \% \mathrm{Zn}$ ) are usually processed by extrusion, forging or rolling. Although these materials are of widespread use, few detailed studies of the flow behavior of brass at high temperature are available. The hot workability of a CW602N brass $(\mathrm{Cu}-36.5 \% \mathrm{Zn}-2 \% \mathrm{~Pb})$ was thus investigated by torsion testing in the temperature range between 550 and $800{ }^{\circ} \mathrm{C}$, under equivalent strain rates ranging from 0.01 to $10 \mathrm{~s}^{-1}$. The peak flow stress dependence on temperature and strain rate was described by the well-known Garofalo equation, with a stress exponent close to 4 and $Q=220 \mathrm{~kJ} \mathrm{~mol}^{-1}$. A considerably larger scatter of the experimental data was observed in the high temperature range. The detailed microstructural analysis of the deformed samples by scanning electron microscopy revealed substantial differences among the samples deformed in the low temperature regime and those torsioned at 750 and $800{ }^{\circ} \mathrm{C}$. These differences were analyzed and discussed to rationalize the different mechanical responses observed in the two hot-deformation regimes.
\end{abstract}

DOI: 10.12693 /APhysPolA.128.726

PACS: 81.05.-t, 81.05.Bx, 81.20.-n, 81.40.Lm

\section{Introduction}

The recent introduction of finite element modelling (FEM) codes to simulate hot working processes (see, for an example, [1]), has highlighted the need for quantifying the mechanical response of the involved material, in term of constitutive equations relating strain, strain rate, temperature and flow stress. The high temperature deformation of single-phase $\alpha$-brass has been considered in several studies [2-5], which analyzed in most cases the creep response of the $\mathrm{Cu}-30 \% \mathrm{Zn}$ alloy [2-4]. Among the most recent publications, only in one case [5] the hot workability of $\mathrm{Cu}-30 \% \mathrm{Zn}$ was investigated by torsion testing. In this study, the flow stress $(\sigma)$ was related to strain rate $(\dot{\varepsilon})$ and temperature $(T)$ by the well-known Garofalo equation,

$$
\alpha \dot{\varepsilon}=A\left[\sinh \left(\alpha^{\prime} \sigma\right)\right]^{n} \exp (-Q / R T),
$$

where $\alpha^{\prime}\left[\mathrm{MPa}^{-1}\right]$ and $\left.A\left[\mathrm{~s}^{-1}\right)\right]$ are material parameters, $R$ is the gas constant, $n$ is the stress exponent and $Q$ is the activation energy for hot working. Equation (1a) was here rewritten in the form

$$
\dot{\varepsilon}=A[\sinh (\alpha \sigma / G)]^{n} \exp (-Q / R T),
$$

where $G$ is the elastic modulus in shear, $\alpha$, now dimensionless, is again a material parameter. Pernis and co-workers [5] obtained for the $\mathrm{Cu}-30 \% \mathrm{Zn}, n=4.3$ and $Q=180 \mathrm{~kJ} / \mathrm{mol}$. Not surprisingly, these values are very close to those calculated by Raj [4] by analyzing the creep response of a similar material $(n=4.1-5.4$ and $Q=175 \mathrm{~kJ} / \mathrm{mol}$ ).

The increase in $\mathrm{Zn}$ content leads to the formation of the bcc $\beta^{\prime}$ ordered phase, which at high temperature evolves in the disordered bcc $\beta$ solid solution; the resulting $\alpha-\beta$ microstructure of the $\mathrm{Cu}-40 \% \mathrm{Zn}$ brass, at working temperatures, even undergoes superplastic

\footnotetext{
* corresponding author; e-mail: s.spigarelli@univpm.it
}

deformation [6-9], due to extensive grain boundary sliding along the $\alpha / \beta$ interfaces $[10,11]$. An analysis of the peak flow stress data presented by Xiao et al. [12] in their investigation of the hot workability of a $\mathrm{Cu}-38 \% \mathrm{Zn}$ shows that, in this $\alpha-\beta$ brass, the stress exponent is slightly lower than in $\mathrm{Cu}-30 \% \mathrm{Zn}(n=3.9)$, while the activation energy is substantially higher $(Q=257 \mathrm{~kJ} / \mathrm{mol})$. Similar values $(n=3.9, Q=222 \mathrm{~kJ} / \mathrm{mol})$ can be obtained by fitting the data presented by Padmavardhani and Prasad [13] for a $\mathrm{Zn}-39.5 \% \mathrm{Zn}-3 \% \mathrm{~Pb}$ brass. Although one can reasonably wonder if $\mathrm{Pb}$ could play a role in determining the material response, the presence of this alloying element, which is liquid at the hot-working temperature, was shown to not affect the Arrhenius plots used for the calculation of the activation energy [14]. For this reason, any effect of $\mathrm{Pb}$ addition in leaded brasses is usually neglected.

A further increase of the $\mathrm{Zn}$-content above $40 \%$ causes the progressive decrease of the volume fraction of $\alpha$ phase, until, for a $\mathrm{Cu}-44 \% \mathrm{Zn}$, the microstructure is composed entirely by $\beta$-phase. The use of Eq. (1) to interpolate the peak flow stresses obtained in [13] by testing in compression a $\mathrm{Cu}-44 \% \mathrm{Zn}$, results in $n=3$, and $Q \approx$ $100 \mathrm{~kJ} / \mathrm{mol}$. It is thus plainly obvious that the magnitudes of the stress exponent and of the activation energy for hot working strongly depend on the initial microstructure of the considered brass. While $n$ seems to monotonically decrease with increase of the $\mathrm{Zn}$ content, $Q$ is relatively high for pure copper $(201 \mathrm{~kJ} / \mathrm{mol}$, activation energy for self-diffusion) [2], decreases down to $175 \mathrm{~kJ} / \mathrm{mol}$ for $30 \% \mathrm{Zn}$ [4], then increases up to $250 \mathrm{~kJ} / \mathrm{mol}$ and above, to again decrease down to $100 \mathrm{~kJ} / \mathrm{mol}$ when the $\mathrm{Zn}$ content is sufficiently high to produce a single-phase $\beta$-microstructure.

In this context, the aim of the present study is to analyze the hot workability of a $\mathrm{Cu}-36.5 \% \mathrm{Zn}-2 \mathrm{~Pb}$ leaded brass, in order to establish the constitutive equation relating flow stress and deformation conditions. 


\section{Experimental}

The alloy considered in the present study was the CW602N brass $(\mathrm{Cu}-36.5 \% \mathrm{Zn}-2 \% \mathrm{~Pb}-\mathrm{As}$, composition in $\mathrm{wt} \%)$. The material was tested in torsion; the hot torsion test is capable of producing strains of the order of 100 in ductile materials without the instabilities which cause barrelling and necking in compression and tension, respectively. When the shear stresses and strains obtained in torsion are converted into equivalent tensile stresses and strains, for example according to the von Mises criterion, torsion flow curves agree very well to tension or compression flow curves for the same strain rate and temperature. For this reason, the torque $M$ and the number of revolutions $N$ were converted to von Mises equivalent stress $\sigma$ and equivalent strain $\varepsilon$ at the surface

$$
\begin{aligned}
& \sigma=\frac{\sqrt{3} M}{2 \pi r^{3}}\left(3+n^{\prime}+m^{\prime}\right), \\
& \varepsilon=\frac{2 \pi N r}{\sqrt{3} L}
\end{aligned}
$$

where $r$ and $L$ are, respectively, the radius and the length of the gauge, $m^{\prime}=(\partial \log M / \log \dot{N})$ is determined at constant strain, and $n^{\prime}=(\log M / \partial \log N)$ at constant strain rate. For the peak stress condition, clearly $n^{\prime}=0$. For the sake of simplicity, $m^{\prime}$ (which was estimated to be 0.15 and 0.23 at 550 and $700^{\circ} \mathrm{C}$, respectively) was also assumed to be equal to 0 , leading to an underestimation of the flow stress which not exceeded $8 \%$. The surface equivalent strain rates were $10^{-2}, 10^{-1}, 1$ and $10 \mathrm{~s}^{-1}$. The specimens for torsion tests, $10 \mathrm{~mm}$ in diameter with a gauge length of $15 \mathrm{~mm}$, were strained, by a computercontrolled hot torsion machine at 550, 600, 650, 700, 750 and $800^{\circ} \mathrm{C}$. The samples were heated by a high frequency induction coil at $1{ }^{\circ} \mathrm{C} / \mathrm{s}$ from room temperature to the testing temperature and maintained at this temperature for $300 \mathrm{~s}$. Subsequently the samples were strained up to rupture. Ruptured samples were quenched by a waterjet.

Samples for scanning electron microscopy were obtained from the as received alloy and from the outer portion of the torsioned specimens. Standard grinding and polishing metallographic techniques were used to prepare the samples for etching with Nital (nitric acid in distilled water).

\section{Results and discussion}

Figure 1a shows representative equivalent stress vs. equivalent strain curves. In general, the curves present a maximum, for strains ranging between 0.7 and 1.2 ; the equivalent strain to fracture, presented in Fig. 1b, decreases with increasing strain rate. The lowest values are observed at $550{ }^{\circ} \mathrm{C}$; no dependence of the strain to fracture on temperature was then observed between 600 and $700^{\circ} \mathrm{C}$. Above this temperature range, the equivalent strain to fracture in torsion exhibits a significant increase with temperature. The analysis of Fig. 1b thus seems to
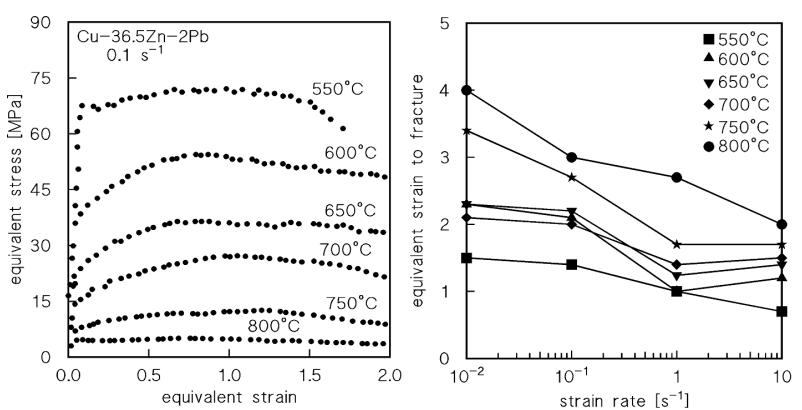

Fig. 1. a) Representative equivalent stress vs. equivalent strain curves in torsion; (b) equivalent fracture strain as a function of testing temperature and strain rate.

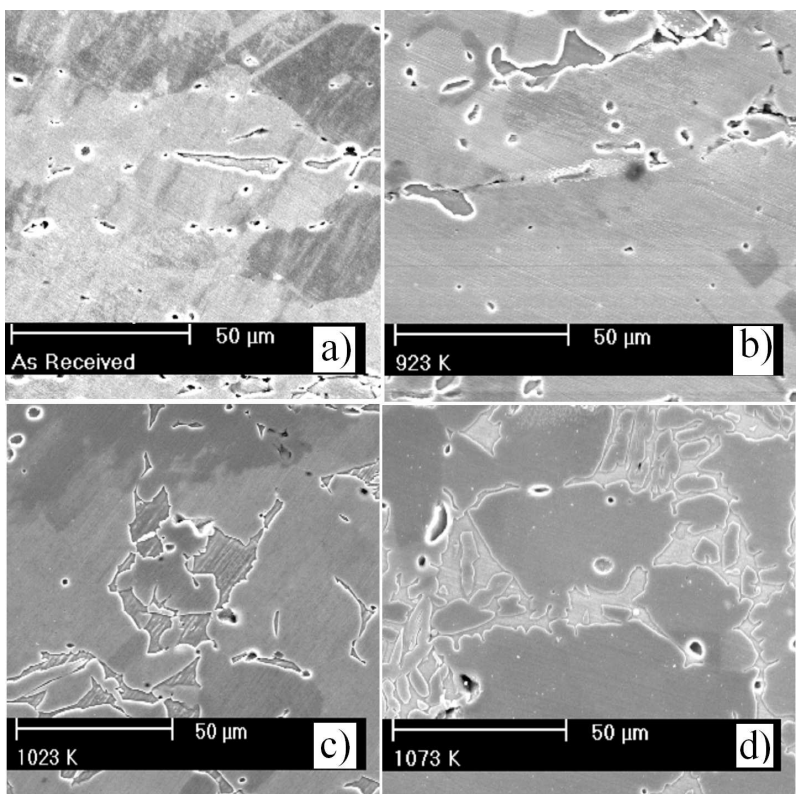

Fig. 2. Microstructure in as received condition (a) and after torsion under $0.01 \mathrm{~s}^{-1}$ : (b) $650{ }^{\circ} \mathrm{C}$ (strain $=2.2$ ); (c) $750{ }^{\circ} \mathrm{C}$ (strain $\left.=3.4\right) ;($ d $) 800^{\circ} \mathrm{C}($ strain $=4.0)$. The $\alpha$-grains constitute the grey matrix, while the particles on grain boundaries are $\beta / \beta^{\prime}$ bcc phase.

suggest that at 750 and $800{ }^{\circ} \mathrm{C}$ the microstructure undergoes an important change that significantly increases the ductility of the alloy.

Figure 2 shows the microstructure of the as received alloy, and after straining at 650,750 and $800^{\circ} \mathrm{C}$. Figure $2 \mathrm{a}$ clearly shows the presence in as received condition of a minor but not negligible amount of $\beta$ or $\beta^{\prime}$ phase (the elongated particles in the matrix of $\alpha$-grains). Although heating up to $650{ }^{\circ} \mathrm{C}$ causes only a moderate increase in the presence of the bcc phase, at 750 and $800{ }^{\circ} \mathrm{C}$ massive blocks of $\beta$ appear at the grain boundaries.

Figure 3 shows the $\mathrm{Cu}-\mathrm{Zn}$ phase diagram [15]; the experimental conditions used to test the hot workability of different brasses are superimposed on the graph. In can be easily observed that, in equilibrium conditions, while in the case of the $\mathrm{Cu}-40 \% \mathrm{Zn}$, the alloy is two-phase in the 


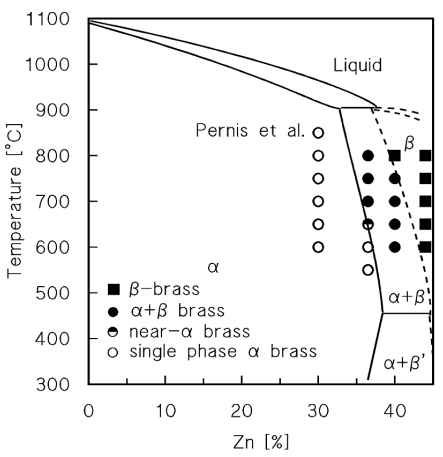

Fig. 3. $\mathrm{Cu}-\mathrm{Zn}$ phase diagram [15]; symbols represent the testing temperature investigated in this study, and in literature for $\mathrm{Cu}-30 \% \mathrm{Zn}[5], \mathrm{Cu}-40 \% \mathrm{Zn}$ [13] and $44 \% \mathrm{Zn}$, respectively [13].

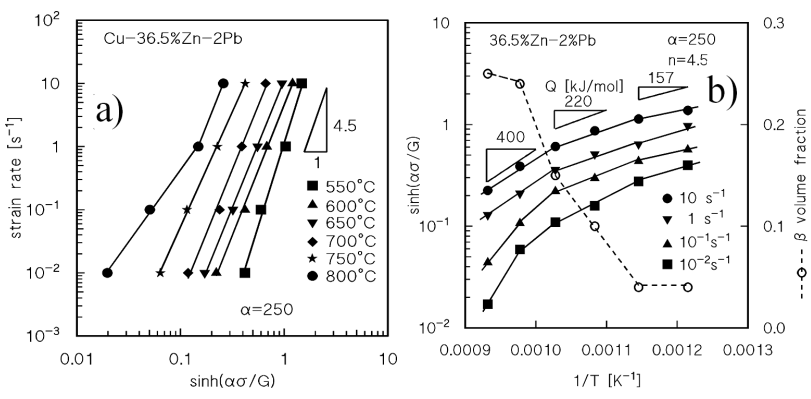

Fig. 4. Peak flow stress dependence on strain rate as a function of temperature (a) and plot used for the calculation of the hot deformation activation energy; the graph also illustrates the volume fraction of $\beta$ phase as measured in the sample torsioned at $0.01 \mathrm{~s}^{-1}(\mathrm{~b})$.

whole range between 550 and $750^{\circ} \mathrm{C}$, the $\mathrm{Cu}-36.5 \% \mathrm{Zn}$ brass of the present study, has a single phase microstructure below $700^{\circ} \mathrm{C}$, while becomes two-phase above this temperature. The presence of either $\beta$ or $\beta^{\prime}$-phase at room temperature, attested in Fig. 2a, and confirmed in the literature for similar alloys [16], is thus presumably the effect of non-equilibrium transformations during material processing.

Figure $4 \mathrm{a}$ plots the peak flow stress as a function of strain rate for the investigated alloy; the figure shows that, with $\alpha=250$, a reasonably constant slope of the curves is obtained between 550 and $750^{\circ} \mathrm{C}$, with $n=4.5$. A different behavior is observed at $800^{\circ} \mathrm{C}$, in particular in the low strain rate regime, where a significantly lower stress exponent is obtained.

The activation energy for high deformation is usually calculated by plotting the $\sinh (\alpha \sigma / G)$ as a function of $1 / T$ (Fig. 4b); in principle the data, as long as the activation energy is constant, should align on straight lines of slope $S$, where

$$
Q=2.3 n R S \text {. }
$$

In the present case, the data rather align on curves whose slope markedly increases with increase of temperature. In the low temperature regime, where the $\beta$-content is lower, the apparent activation energy is close to $157 \mathrm{~kJ} / \mathrm{mol}$.
This value is fully consistent with those estimated in $\mathrm{Cu}-$ $30 \% \mathrm{Zn}$ in $[4,5](175-180 \mathrm{~kJ} / \mathrm{mol})$, since both $Q_{\mathrm{Zn}}^{*}$ and $Q_{\mathrm{Cu}}^{*}$ (activation energy for tracer diffusion of $\mathrm{Zn}$ and $\mathrm{Cu}$ in brass, respectively) decrease with increase of $\mathrm{Zn}$ content [17]. Equation (1) can be rewritten [4] as

$$
\dot{\varepsilon}=A_{0} \tilde{D}[\sinh (\alpha \sigma / G)]^{n},
$$

where $\tilde{D}$ is the complex diffusion coefficient for dislocation climb, which, following Fuentes-Samaniego and Nix [18, 19], can be expressed as a function of the atomic fraction of $\mathrm{Cu}$ and $\mathrm{Zn}\left(N_{\mathrm{Cu}}\right.$ and $\left.N_{\mathrm{Zn}}\right)$ in the form

$$
\begin{aligned}
& \tilde{D}=\tilde{D}_{0} \exp \left(-Q_{c} / R T\right)= \\
& \quad\left(N_{\mathrm{Cu}} D_{\mathrm{Cu}}^{*}+N_{\mathrm{Zn}} D_{\mathrm{Zn}}^{*}\right) / 0.78 \\
& D_{\mathrm{Cu}}^{*}=D_{0 \mathrm{Cu}}^{*} \exp \left(-Q_{\mathrm{Cu}}^{*} / R T\right), \\
& D_{\mathrm{Zn}}^{*}=D_{0 \mathrm{Zn}}^{*} \exp \left(-Q_{\mathrm{Zn}}^{*} / R T\right) .
\end{aligned}
$$$$
\text { with }
$$

Since, according to Anusavice and DeHoff, also the diffusion constants $D_{0 \mathrm{Zn}}^{*}$ and $D_{0 \mathrm{Cu}}^{*}$ decrease with increase of the $\mathrm{Zn}$ content above $20 \%$, the complex diffusion coefficient for climb can be expected to monotonically decrease in this composition range. Thus, the activation energy for climb, $Q_{c}$, should be well below $175 \mathrm{~kJ} / \mathrm{mol}$ when $\mathrm{Zn}=36.5 \%$.

As temperature rises, the increase in volume fraction of the softer bcc phase causes the marked softening of the alloy. The higher the $\beta$-amount, the softer the material becomes, leading to a progressive curvature of the $\log (\sinh (\alpha \sigma / G))$ vs. $1 / T$ plot. This effect, in turns, leads to progressively higher $Q$-values when the activation energy is calculated by Eq. (3). Thus, this $Q$ value can be more correctly identified as an apparent activation energy, since it does not depend only on the diffusivities of the alloy, but is greatly affected by the presence of a softer phase, whose amount in turn depends on temperature. If the whole temperature range above 550 up to $700{ }^{\circ} \mathrm{C}$ is considered, an average value of the apparent activation energy of $220 \mathrm{~kJ} / \mathrm{mol}$ can be estimated. This value is fully consistent with those, above mentioned, for $\alpha-\beta$ alloy, which is not surprising, since at $650-700^{\circ} \mathrm{C}$ the alloy contains $10-15 \%$ of $\beta$-phase.

Figure 5a shows the Zener-Hollomon parameter $Z=$ $\dot{\varepsilon} \exp (Q / R T)$, with $Q=220 \mathrm{~kJ} / \mathrm{mol}$; as expected, almost all the experimental data quite closely align on a same straight line of slope $n=4.5$, except the low-strain rate results at 750 and $800^{\circ} \mathrm{C}$. The low strength observed in these conditions corresponds to the high values of equivalent strain to fracture shown in Fig. 1b, and both these phenomena can be attributed to the increased presence of $\beta$-phase.

The above qualitative discussion on the effect of the increased presence of a soft-phase (the $\beta$-phase) in a hardmatrix (the $\alpha$-phase), clearly suggests that the material of the present study could be efficaciously described by the composite model based on the rule of mixtures. Thus, the material strength can be calculated as 


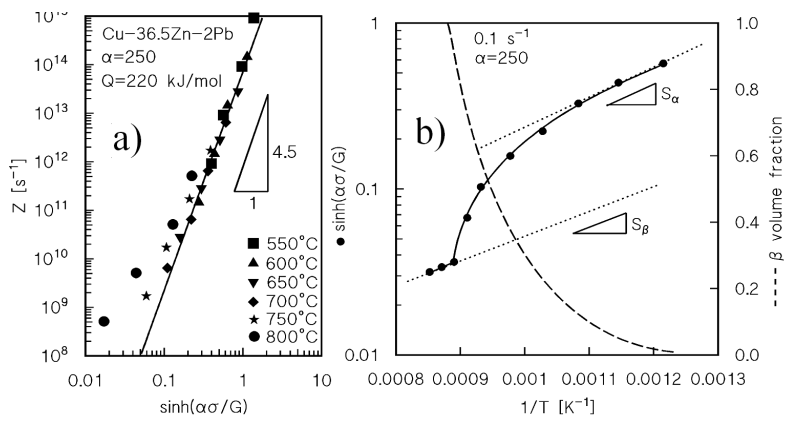

Fig. 5. Zener-Hollomon parameter as a function of peak flow stress (a) and same plot of Fig. $4 \mathrm{~b}$ at $0.1 \mathrm{~s}^{-1}$, for the alloy of the present study, containing the equilibrium volume fraction of $\beta$-phase (broken line in the graph), whose strength was recalculated by the composite model (b). The $S_{\alpha}$ and $S_{\beta}$ slope give, through Eq. (3), $Q=157$ and $92 \mathrm{~kJ} / \mathrm{mol}$, respectively.

$$
\sigma=\left(1-f_{s}\right) \sigma_{h}+f_{s} \sigma_{s},
$$

where the suffixes $s$ and $h$ denote the soft and hard regions, respectively, and $f_{s}$ is the volume fraction of the soft $\beta$-phase [20]. According to Fig. 3 an alloy containing $36.5 \% \mathrm{Zn}$ (corresponding to a $\mathrm{Cu} / \mathrm{Zn}$ ratio close to 1.68 , which, translated into a binary alloy composition, corresponds to $\mathrm{Cu}-37.2 \% \mathrm{Zn}$ ) could be described by a composite formed by hard $\alpha$-phase with $36 \% \mathrm{Zn}$, and a soft $\beta$-phase with $42-44 \%$ Zn. Each phase obeys a constitutive equation in the form of Eq. (1), with $\alpha=350, n=3$, $Q=92 \mathrm{~kJ} / \mathrm{mol}$ and $A=1.44 \times 10^{7} \mathrm{~s}^{-1}$ for the soft phase $(\mathrm{Zn}=44 \%)$, and $\alpha=250, n=4.5, Q=157 \mathrm{~kJ} / \mathrm{mol}$ and $A=6.6 \times 10^{9} \mathrm{~s}^{-1}$ for the hard phase $(\mathrm{Zn}=36 \%$ ) (see Ref. [20] for a detailed discussion on the calculation of these parameters). Combination of these data with Eq. (7), for an alloy containing the equilibrium volume fraction of $\beta$-phase, gives the plot presented in Fig. 5b (with $\alpha=250$ ). The analogy between Figs. $4 \mathrm{~b}$ and 5b is self-apparent, thus attesting that the non-monotonic value of the apparent activation energy for hot working is an artefact due to the presence of a composite-like microstructure.

\section{Conclusions}

The hot workability of a $\mathrm{Cu}-36.5 \% \mathrm{Zn}-2 \mathrm{~Pb}$ brass was investigated by torsion testing between 550 and $800^{\circ} \mathrm{C}$. Two different regimes were identified: (i) a low temperature regime $\left(550-700{ }^{\circ} \mathrm{C}\right)$, where the volume fraction of soft $\beta$-phase remained below $15 \%$, the stress exponent in the Garofalo equation was close to $n=4.5$, the average value of the apparent activation energy for deformation was close to $220 \mathrm{~kJ} / \mathrm{mol}$, and the equivalent strain to fracture was relatively low; (ii) a high temperature regime $\left(750-800^{\circ} \mathrm{C}\right)$, characterized by higher volumes of soft $\beta$-phase, by very high values of the apparent activation energy for hot working (300-400 kJ/mol) and by high values of the equivalent strain to fracture.
The differences in hot workability, as well as the anomalous dependence of the apparent activation energy for hot-working, are considered to be effects of the microstructural instability, which leads to the formation of higher amounts of $\beta$-phase as temperature is increased above $650^{\circ} \mathrm{C}$.

\section{References}

[1] J.R. Cho, H.S. Jeong, D.J. Cha, W.B. Bae, J.W. Lee, J. Mater. Proc. Tech. 160, 1 (2005).

[2] R.M. Bonesteel, O.D. Sherby, 0.1016/00016160(66)90096-4Acta Metall. 14, 385 (1966).

[3] S.A. Mahmoud, M.A. Semary, Z.M. Farid, N. ElNaquib, Mater. Sci. Eng. A 118, 107 (1989).

[4] S.V. Raj, J. Mater. Sci. 26, 3533 (1991).

[5] R. Pernis, J. Kasala, J. Boruta, Kovove Mater. 48, 41 (2010).

[6] M. Suery, B. Baudelet, J. Mater. Sci. 8, 363 (1973).

[7] J.W.D. Patterson, N. Ridley, J. Mater. Sci. 16, 457 (1981).

[8] D. Hua, W. Qingling, M. Lonxiang, J. Mater. Sci. 27, 607 (1992).

[9] K. Neishi, Z. Horita, T.G. Langdon, Scr. Mater. 45, 965 (2001).

[10] T. Chandra, J.J. Jonas, D.M.R. Taplin, J. Mater. Sci. 13, 2380 (1978).

[11] H. Miyamoto, T. Tanaka, T. Mimaki, R. Matsubara, N. Ashie, S. Miura, Mater. Sci. Eng. A 380, 34 (2004).

[12] Y.-H. Xiao, C. Guo, X.-Y. Guo, Mater. Sci. Eng. A 528, 6510 (2011).

[13] D. Padmavardhani, Y.V.R.K. Prasad, Metall. Trans. 22A, 2993 (1991).

[14] B.L. Vaandrager, G.M. Pharr, Scr. Metall. 18, 1337 (1984).

[15] A.P. Miodownik, in: ASM Handbook, Vol. 3, 1987, p. 2.

[16] V. Buršiková, J. Buršik, V. Navrátil, K. Milička, Mater. Sci. Eng. A 324, 235 (2002).

[17] K.J. Anusavice, R.T. DeHoff, Metall. Trans. 3, 1279 (1972).

[18] R. Fuentes-Samaniego, W.D. Nix, Scr. Metall. 15, 15 (1981).

[19] R. Fuentes-Samaniego, W.D. Nix, G.M. Pound, Acta Metall. 29, 487 (1981).

[20] S. Spigarelli, M. El Mehtedi, M. Cabibbo, F. Gabrielli, D. Ciccarelli, Mater. Sci. Eng. A 615, 331 (2014). 